\title{
Cocrystals of Ethenzamide With 2-Nitrobenzoic Acid - Conformational Analysis, MD Simulations And DFT Investigations
}

Y. Sheena Mary ( $\sim$ marysheena2018@rediffmail.com )

Researcher, Thushara, Neethinagar-64, Kollam https://orcid.org/0000-0002-9082-3670

\section{Y. Shyma Mary}

Thushara

\section{Razieh Razavi}

University of Jiroft

\section{Research Article}

Keywords: DFT, MD simulations, MEP, Ethenzamide, 2-Nitrobenzoic acid

Posted Date: August 4th, 2021

DOl: https://doi.org/10.21203/rs.3.rs-729000/v1

License: (c) (1) This work is licensed under a Creative Commons Attribution 4.0 International License.

Read Full License 


\section{Abstract}

In crystal engineering and pharmaceutical chemistry, cocrystals have a wide range of applications. Ethenzamide (EA) is found to form cocrystal with 2-nitrobenzoic acid (NBA). Geometry properties like stability energy, charge distribution, bond length, electronic properties and thermodynamic characteristics have been analyzed. The $\mathrm{C}-\mathrm{H} . . . \mathrm{O}$ hydrogen bond involves $\mathrm{C}-\mathrm{H}$ of EA and oxygen of NBA. Configuration with the angle, N3-C4-C5-C6 gives the lowest energy conformation. Partition coefficient value suggests that EA-NBA has pharmaceutics behavior. RMSD values show the simulation's relative stability and the complexes, remained stable throughout.

\section{Introduction}

Cocrystals have grown in popularity over the last 20 years as a result of their superior medicinal properties relative to the parent drug. Cocrystals are multi-component structures in which each compound is neutral and solid at room temperature [1,2]. Cocrystallization is particularly important in the pharmaceutical industry because cocrystals of an API have better biopharmaceutical qualities than pure drug $[3,4]$. Because of the variations in solubility of the individual components, standard solution based approaches are not always effective in cocrystal preparation. Cocrystal processing has demonstrated high efficiency using solid state methods $[5,6]$. Various approaches have been used to better understand cocrystallization [7-9]. Du et al. reported the cocrystals of piracetam with hydroxybenzoic acids [10,11]. Ethenzamide is an analgesic and antipyretic NSAID [12] and used in conjunction with active ingredients and its crystal structure was only recently reported $[13,14]$. Kozak et al. reported the characterization of cocrystals of ethenzamide [15]. The effect of external factors on ethenzamide-glutaric acid cocrystal was studied spectroscopically by Kozak and Pindelska [16]. Using ethenzamide, technologies in tablet production was recently reported [17]. Experimentally and theoretically, Aravinthraj et al. investigated the molecular interactions of 2-nitrobenzoic acid with other compounds [18]. 2-Nitrobenzoic acid can be used as a bacterial strain's growth supplement [19]. Hariprasad et al. reported the synthesis of cocrystals of ethenzamide [20]. DFT and MD simulations of EA-NBA are reported in the present work due to the importance of cocrystals in medicinal chemistry.

\section{Methods}

Geometry (Fig. 1) properties like stability energy, charge distribution, bond length, electronic properties ( $\mu$, $a, \sigma, \chi, \eta, \omega, \mu)$ and thermodynamic characteristics such as $\left(E, C_{v}, S\right.$ and $\left.\Delta G\right)$ have been calculated by B3LYP/6-311++(2d,2p) with Gaussian and Gaussview software [21, 22]. Some of pharmo-kinetic properties also have been calculated. The selected protein-drug and complex was subjected to MD simulation in Gromacs-2019.4 and as in literature [23-26].

\section{Results And Discussion}

\section{Conformational analysis}


To find lowest energy configuration, potential energy scans are performed through five torsion angles (Table 1 and Fig.S1) out of which the configuration $\mathrm{t}(5)$ (N3-C4-C5-C6) gives the lowest one at $0.0^{\circ}$. All the conformations give another global minimum at $120.0,100.0,80.0,130.0$ and $130.0^{\circ}$ for $\tau(1)$ to $\tau(5)$ conformations, with higher energy. For further analysis, $\tau(5)$ conformation is considered [27].

Table 1

Different conformations and energy values

\begin{tabular}{|lllll|}
\hline SI.No. & Torsion angle & Torsion angle $\left(^{\circ}\right)$ & Energy in (Hartree) & $\begin{array}{l}\text { Relative energy } \\
\text { (Hartree) }\end{array}$ \\
\hline$\tau(1)$ & C6-02-C8-C12 & 0.0 & -1166.65529 & 0.00035 \\
\hline$\tau(2)$ & C8-02-C6-C5 & 180.0 & -1166.65525 & 0.00039 \\
\hline$\tau(3)$ & C8-02-C6-C10 & 0.0 & -1166.65556 & 0.00008 \\
\hline$\tau(4)$ & N3-C4-C5-C7 & 180.0 & -1166.65543 & 0.00021 \\
\hline$\tau(5)$ & N3-C4-C5-C6 & 0.0 & -1166.65564 & 0.00000 \\
\hline
\end{tabular}

\section{Spectroscopic, geometric, chemical and electronic properties}

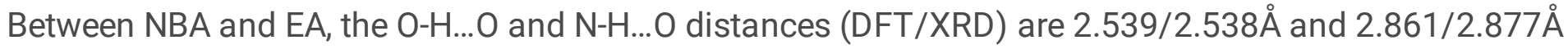
with torsion angles, $170.3 / 173.3^{\circ}$ and $11.3 / 171.8^{\circ}$. The $\mathrm{C}-\mathrm{H}$...O hydrogen bond $(3.631 / 3.474 \AA$ and $161.8 / 168.4^{\circ}$ ) involves $\mathrm{C}-\mathrm{H}$ of EA and oxygen of NBA acid group. The interactions are evident from the distances (DFT/XRD) as: C12-H14 ...025 = 2.557/3.412 $\mathrm{A}, \mathrm{N} 3-\mathrm{H} 18 \ldots \mathrm{O} 2=1.927 / 2.619 \AA, \mathrm{C} 33-\mathrm{H} 38 \ldots \mathrm{O} 232=$

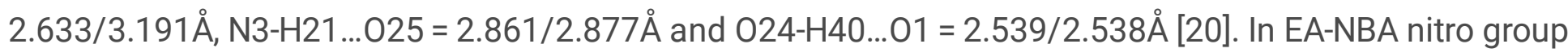
oxygens are involved in hydrogen bond. The $C O$ bond lengths (DFT/XRD) are $C 4=01=1.2813 / 1.2423 \AA$, $\mathrm{C} 30=025=1.2513 / 1.2043 \AA$, C30-024 $=1.3343 / 1.3023 \AA$, $C 6-02=1.3949 / 1.3613 \AA$ and $\mathrm{C} 8-02=$ $1.4678 / 1.4303 \AA$ while NO lengths are 1.2591, 1.2647/1.2164, 1.2084 $[20]$. Correlation coefficient (R) and standard deviations were calculated for statistical validation between the geometrical parameters (table S1) obtained from DFT optimization and crystal structure data. The correlation coefficient for bond lengths and bond angles were found to be 0.9961 and 0.9541 , respectively. From the curve fitting analysis (Fig.S2), the standard deviations for bond lengths and angles are 0.0201 and 1.4562, respectively. It is found that the structural parameters are statistically closed to the experimental results [28].

The important functional groups of vibrational modes (table S2) of EA-NBA are: $3423 \mathrm{~cm}^{-1}$ (IR), 3487 $\mathrm{cm}^{-1}$ (DFT) (NH2); 3135, 3082, 2973, 2905/3128, 3080, 2974, $2925 \mathrm{~cm}^{-1}$ (CH); 2355/2363 cm-1 (OH); 1694, 1535/1660, $1540 \mathrm{~cm}^{-1}$ (C = 0); 1416 and $1253 \mathrm{~cm}^{-1}$ (DFT values NO2); 1215, 1070, 1016/1209, $1075,1016 \mathrm{~cm}^{-1}$ (CO) [29, 30]. In pristine EA and NBA, C = 0 is observed at 1625 and $1671 \mathrm{~cm}^{-1}$ [20].

Strong hyper conjugative interactions (tables S3 and S4) are present in EA-NBA due to hydrogen bonding and is given as (energy in $\mathrm{kcal} / \mathrm{mol}): 032 \rightarrow(\mathrm{N} 26-027)(144.54) ; 027 \rightarrow(\mathrm{N} 26-032)(18.98) ; 025 \rightarrow(\mathrm{O} 24-\mathrm{C} 30)$ (21.98); $024 \rightarrow(\mathrm{O} 25-\mathrm{C} 30)(59.55) ; \mathrm{O} 2 \rightarrow(\mathrm{C} 6-\mathrm{C} 10)(27.32)$ and due to this interactions, there is a shift of the 
IR wavenumbers [31, 32]. TD-DFT results give two electronic absorptions (Fig.S3) at 360 and $323 \mathrm{~nm}$ with oscillator strengths of 0.0099 and 0.0003 having contributions, $\mathrm{HOMO}(\mathrm{H})-5$ to $\mathrm{LUMO}(\mathrm{L})(16 \%), \mathrm{H}-4$ to $\mathrm{L}(15 \%), \mathrm{H}-1$ to $\mathrm{L}(40 \%)$ and $\mathrm{H}$ to $\mathrm{L}(100 \%)$.

Research on subjects of crystal engineering and supra molecular synthesis of cocrystals is large and growing $[33,34]$. In order to complement these themes, we would like to discuss the preliminary actions that should be addressed (before any reaction take place!) when aiming to maximize the experimental efficacy of developing co-crystalline materials. The FDA defines co-crystals as "crystalline materials composed of two or more different molecules, typically active pharmaceutical ingredient (API) and cocrystal formers ('coformers'), in the same crystal lattice" [34]. Co-crystallization is a promising method for modifying and improving an API's physicochemical properties without causing covalent modifications to the drug molecule. Co-crystals are frequently used to address the poor solubility and bioavailability of BCS class II and IV medications, which account for $70 \%$ of all therapeutic candidates in development [33]. Chemical stability, hygroscopicity, mechanical characteristics, and flow qualities have been enhanced as a result of cocrystal formation. Co-crystallization can also be utilized for purification and enantiomeric separation [33].

In order to recognize the bio-pharmaceutic behavior of this compound, the optimization process has been done by B3LYP/6-311++(2d,2p). In Fig.S4 surface of cocrystal showed to recognize the active surface of compound in biological behavior. HOMO and LUMO energy can apply to determine the electronic parameters and reactivity parameters and to show the positive and negative place of compound for recognizing the active site in molecule Fig. 2. Fig.S5 shows the intermolecular and $\mathrm{H}$ bond interaction by green color line to determine the active site of molecule for getting interaction inside of molecule and the active site for getting $\mathrm{H}$ interaction by DNA and protein and bio-molecule. A map which shows the attractive or repulsive force felt by a fixed charged (often a point positive charge, i.e., a proton) at points that are equidistant from molecular surface. In Fig.S6, ESP map of cocrystal compound demonstrated for accepting HOMO and LUMO and charge distribution of cocrystal compound. Critical points are points where the first derivatives of $\rho(r)$ vanish and thus they determine the position of extrema in the charge density (minima, maxima, saddle points). Fig.S7 demonstrate critical points in cocrystal compounds. In order to show the molecule properties of cocrystal compound Fig.S8 plotted these properties to make better results from geometry and topological analysis.

By consideration chemical geometry of chemical compound, the structure analysis will be obtained for recognition the biochemical manner. When the electron structure of chemical compounds demonstrated, the electronics and thermodynamic and pharmaceutics properties will get and calculated in good manner and the researcher can result the bioactive behavior of molecules. In order to recognize the chemical reactivity and pharmaceutical behavior, Table 2 obtained the necessary parameters that lead to get best results to show pharmaceutics behavior. In Table 2 the softness, hardness, electronegativity, electropositivity, chemical potential are the electronic parameters for determining the chemical reactivity. Log $p$, surface area, volume, hydration energy and polarizability demonstrate the pharmaceutical properties. Energy and $\mathrm{C}_{\mathrm{v}}$ are thermodynamic parameters. 
Table 2 Some parameters of EA-NBA

\begin{tabular}{|ll|}
\hline Parameter & value \\
\hline Electronic Energy(kJ) & $-5.15 \times 10^{-18}$ \\
\hline Polarizability(a.u.) & 237.43 \\
\hline Dipole moment(D) & 3.83 \\
\hline Energy thermal(kCal/mol) & 206.948 \\
\hline $\mathrm{C}_{\mathrm{v}}(\mathrm{kcal} / \mathrm{molK})$ & 82.706 \\
\hline $\mathrm{S}(\mathrm{kcal} / \mathrm{molK})$ & 170.179 \\
\hline logP & 5.17 \\
\hline Hydration energy $(\mathrm{kCal} / \mathrm{mol})$ & 18.80 \\
\hline Surface area $\left(\AA^{2}\right)$ & 487.57 \\
\hline Volume $\left(\AA^{3}\right)$ & 931.46 \\
\hline $\mathrm{HOMO}(\mathrm{eV})$ & -8.65 \\
\hline $\mathrm{LUMO}(\mathrm{eV})$ & -5.01 \\
\hline $\mathrm{IP}(\mathrm{eV})$ & 8.65 \\
\hline $\mathrm{EA}(\mathrm{eV})$ & 5.01 \\
\hline$\mu(\mathrm{eV})$ & -6.83 \\
\hline$\omega(\mathrm{eV})$ & 6.40 \\
\hline$\eta(\mathrm{eV})$ & 3.64 \\
\hline$\chi(\mathrm{eV})$ & 6.83 \\
\hline$\sigma(\mathrm{eV})$ & 0.27 \\
\hline
\end{tabular}

A partition coefficient $(P)$ or distribution coefficient $(D)$ is the ratio of a compound's concentrations in a mixture of two immiscible solvents. This ratio represents a comparison of the solute's solubility in two liquids. The partition coefficient describes the concentration ratio of unionized compound species, whereas the distribution coefficient describes the concentration ratio of all compound species (ionized plus un-ionized). Both phases are often solvent in the chemical and medicinal sciences. One of the solvents is usually water, whereas the other is hydrophobic, such as 1-octanol. As a result, the partition coefficient determines whether a chemical substance is hydrophilic ("water-loving") or hydrophobic ("water-fearing"). Hydrophobic medicines with high octanol-water partition coefficients are found in cell lipid bilayers. Hydrophilic medicines on the other hand, are found largely in aqueous environments such 
as blood serum (low octanol/water partition coefficients). According to data in Table 2 cocrystal compound $\log \mathrm{P}=5.17$ obtained this cocrystal compound has pharmaceutics behavior.

\section{Molecular docking and simulation studies}

Ethenzamide is a NSAID with analgesic and antipyretic properties and, title molecule is docked [35-37] with the PDBs, 2ABZ, 5JCL, 3SDP and 2V7B corresponding to mutant of leech carboxypeptidase inhibitor [38], monodehydroascorbate reductase [39], iron superoxide dismutase [40], and benzoate CoA ligase inhibitor [41]. The binding energy and amino acids interactions at the active sites are given in table S5 and Fig.S9. 2ABZ gives maximum global and atomic contact energies and based on this, MD simulations are also carried with this PDB and the ligand.

In our study, crystal structure of C19A/C43A mutant of leech carboxypeptidase inhibitor(2ABZ), APO and complex with selected ligand from docking drug was subjected to molecular dynamics simulation analysis. MD simulation for $100 \mathrm{~ns}$ were done to understand stability of above-mentioned protein-ligand complexes RMSD, RMSF, Rg, H-Bonds (hydrogen bonds), Ligand RMSD, SASA, Secondary structure element analysis and MMPSA calculations were made.

Root mean square deviation is a term to determine differences between the two confirmations. Higher RMSD gives more deviation and the RMSD values are calculated against the simulation timescale of 40 to $100 \mathrm{~ns}$. Average RMSDs from 0 to $100 \mathrm{~ns}$ for APO and drug protein were $0.91 \mathrm{~nm}$ and $0.89 \mathrm{~nm}$. This represents stability of APO and ligand complex in simulation [42]. RMSD results for APO and its complex with ligand are depicted in Fig. 3(a) and (b). During the 100ns simulation, it was observed that the APO and complexes are equilibrated after 40ns of time. The RMSD mean for APO and complexes were calculated from $40 \mathrm{~ns}$ to $100 \mathrm{~ns}$. The amino acids involved in bringing the overall structural deviation are explored in the RMSF plots. The ligand RMSD is used to find the differences between the two confirmations. The ligand RMSD values are calculated against the simulation timescale of 0 to $100 \mathrm{~ns}$. Average drug RMSDs from 0 to $100 \mathrm{~ns}$ for inhibitors were $0.03 \mathrm{~nm}$ which gives the stability of the drug with the protein.

RMSF analysis determines which amino acids of the protein make more vibrations, resulting in the destabilization of protein in presence/absence of the ligands. The RMSF values are calculated against the simulation timescale of 0 to 100ns. The RMSF results for APO and its complex with ligand, chain A and chain B as depicted in Fig. 3(c) and (d). The average RMSF-A and RMSF-B from 0 to 100 ns for APO and drug complex were $0.3 \mathrm{~nm}$ and 0.4 , respectively [43]. Compactness of the protein can be determined by the radius of gyration. Folding and unfolding of the protein was analyzed by the $\mathrm{Rg}$ values against the simulation timescale of 0 to 10,000ps for APO and its complex with ligand. The average Rg from 0 to 100 ns for APO and ligand complexes were 1.6 and $1.05 \mathrm{~nm}$. The RG result of the APO and its complex with ligand as depicted in Fig. 4(a) [44].

The terms "flexibility" and "compactness" are often used interchangeably. To understand the modulation of inhibitors on the protein, SASA changes the compactness of protein. SASA were determined, though 
the variations in SASA values in all of the complexes were quite small. SASA values range from 0 to 100 represented in Fig. 4(b). Average SASAs from 0 to 100 ns for APO and inhibitors ligand were 80 and 81 respectively [45].

The creation of hydrogen bonds stabilizes protein-drug complexes. In our research, hydrogen bonds (Fig. 5) formed in the molecular docking analysis are confirmed by the simulation analysis. The ability to investigate the structural behavior of a protein requires an understanding of secondary structural content. As in Fig.S10(a-d), we evaluated changes in secondary structure in apo and ligand complexes. How much energy is required for the ligand to bind to protein is determined by MMPBSA. The binding energy of DRG was $-135.238+/-21.157 \mathrm{~kJ} / \mathrm{mol}$ (Table 3). MMPSA of complex with ligand is for the last $20 \mathrm{~ns}$ simulation. The active site binding site MMPBSA calculation was carried out and the residues are GLN13, GLN-16, CYS-18, PHE-20, GLU-31, VAL-48, THR-60, THR-61, CYS-62, THR-39, ALA-40, PRO-41, ALA-43, ARG-44 was $-13.7055 \mathrm{~kJ} / \mathrm{mol}$.

Table 3

Binding energies - MMPBSA

\begin{tabular}{|lllll|}
\hline Drug & van der Waal energy & Electrostatic energy & $\begin{array}{l}\text { Polar solvation } \\
\text { energy }\end{array}$ & Binding energy \\
\hline $\begin{array}{l}\text { EA- } \\
\text { NBA }\end{array}$ & $\begin{array}{l}-197.592+/-23.659 \\
\mathrm{~kJ} / \mathrm{mol}\end{array}$ & $\begin{array}{l}-26.367+/-18.352 \\
\mathrm{~kJ} / \mathrm{mol}\end{array}$ & $\begin{array}{l}107.959+/-27.742 \\
\mathrm{~kJ} / \mathrm{mol}\end{array}$ & $\begin{array}{l}-135.238+/-21.157 \\
\mathrm{~kJ} / \mathrm{mol}\end{array}$ \\
\hline
\end{tabular}

\section{Conclusion}

The theoretical spectroscopic analysis together with MD simulations was reported for the cocrystal EANBA. Conformational analysis predicts the lowest energy conformation along the angle N3-C4-C5-C6. Important functional groups are identified and there exist hydrogen bonding within the cocrystal system. ESP map of EA-NBA demonstrated for accepting HOMO and LUMO and charge distribution. The position of extrema in the charge density is determined by critical points, which are sites where the first derivatives of electron density vanish. MD simulations confirmed that formation of hydrogen bonds in the molecular docking. Different parameters obtained from MD simulations give the stability of the complexes.

\section{Declarations}

Funding: N/A

Conflict of interest: The authors declare no competing interests.

Data availability: All data are available on request to the corresponding author

Code availability: N/A

Author's contributions: Conceptualization, Y.Sheena Mary; Methodology, Y.Shyma Mary; Writing original draft, Razieh Razai, Y.Sheena Mary; Writing-review and editing, Y.Sheena Mary, Y.Shyma Mary, Razieh 
Razavi

\section{Ethics approval}

The manuscript is prepared in compliance with the Ethics in Publishing Policy as described in the Guide for Authors

\section{Consent to participate}

The manuscript is approved by all authors for publication

\section{Consent for publication}

The consent for publication was obtained from all participants

\section{References}

[1] G.R.Desiraju, Crystal and cocrystal, CrystEngComm. 5 (2003) 466-467.

https://doi.org/10.1039/B313552G

[2] A.D.Bond, What is a cocrystal? CrystEngComm. 9 (2007) 833-834. https://doi.org/10.1039/B708112J

[3] S.Karki, T.Friscic, L.Fabian, P.R.Laity, G.M.Day, W.Jones, Improving mechanical properties of crystalline solids by cocrystal formation: new compressible forms of paracetamol, Adv. Mater. 21 (2009) 3905-3909. https://doi.org/10.1002/adma.200900533

[4] N.Shan, M.J.Zaworotko, The role of cocrystals in pharmaceutical science, Drug Discov. Today 13 (2008) 440-446. https://doi.org/10.1016/j.drudis.2008.03.004

[5] D.Douroumis, S.A.Ross, A.Bokhodchi, Advanced methodologies for cocrystal synthesis, Adv.Drug Deliv. Rev. 117 (2017) 178-195. https://doi.org/10.1016/j.addr.2017.07.008

[6] S.L.James, C.J.Adams, C.Bolm, D.Braga, P.Collier, T.Friscic, F.Grepioni, K.D.Harris, G.Hyett, W.Jones, Mechanochemistry: opportunities for new and cleaner synthesis, Chem. Soc. Rev. 41 (2012) 413-447. https://doi.org/10.1039/C1CS15171A

[7] K.S.Lee, K.J.Kim, J.Ulrich, In situ monitoring of cocrystallization of salicylic acid-4,4'-dipyridyl in solution using Raman spectroscopy, Cryst. Growth. Des. 14 (2014) 2893-2899.

https://doi.org/10.1021/cg5001864

[8] H.Kulla, S.Greiser, S.Benemann, K.Rademann, F.Emmerling, In situ investigation of a self accelerated cocrystal formation by grinding pyrazinamide with oxalic acid, Molecules 21 (2016) 917. https://doi.org/10.3390/molecules21070917 
[9] A.L.Kelly, T.Gough, R.S.Dhumal, S.Halsey, A.Paradkar, Monitoring ibuprofen- nicotinamide cocrystal formation during solvent free continuous cocrystallization (SFCC) using near infrared spectroscopy as a PAT tool, Int. J. Pharm. 426 (2012) 15-20. https://doi.org/10.1016/j.ijpharm.2011.12.033

[10] Y.Du, H.Zhang, Z.Hong, Using terahertz time domain spectroscopical technique to monitor cocrystal formation between piracetam and 2,5-dihydroxybenzoic acid, Spectrochim. Acta 111 (2013) 192-195. https://doi.org/10.1016/j.saa.2013.03.081

[11] Y.Du, H.Zhang, J.Xue, H.Fang, Q.Zhang, Y.Xia, Y.Li, Z.Hong, Raman and terahertz spectroscopical investigation of cocrystal formation process of piracetam 3-hydroxybenzoic acid, Spectrochim. Acta 139 (2015) 488-494. https://doi.org/10.1016/j.saa.2014.11.109

[12] S.Aoki, T.Mizutani, K.Danjo, Studies on the number of contacts between ibuprofen and ethenzamide using thermal analysis, Chem. Pharm. Bull. 48 (2000) 140-141. https://doi.org/10.1248/cpb.48.140

[13] S.M.Sultan, I.Z.Alzamil, A.M.A.Alrahman, S.A.Altmrah, Y.Asha, Use of cerium(IV) sulphate in the spectrophotometric determination of paracetamol in pharmaceutical preparations, Analyst 111 (1986) 919-921. https://doi.org/10.1039/AN9861100919

[14] K.R.Back, R.J.Davey, T.Grecu, C.A.Hunter, L.S.Taylor, Molecular conformation and crystallization: The case of ethenzamide, Cryst. Growth Des. 12 (2012) 6110-6117. https://doi.org/10.1021/cg301244x

[15] A.Kozak, P.H.Marek, E.Pindelska, Structural characterization and pharmaceutical properties of thee novel cocrystals of ethenzamide with aliphatic dicarboxylic acids, Journal of Pharmaceutical Sciences 108 (2019) 1476-1485. https://doi.org/10.1016/j.xphs.2018.10.060

[16] A.Kozak, E.Pindelska, Spectroscopic analysis of the influence of various external factors on ethenzamide-glutaric acid (1:1) cocrystal formation, European Journal of Pharmaceutical Sciences 133 (2019) 59-68. https://doi.org/10.1016/j.ejps.2019.03.017

[17] K.Matsunami, T.Nagato, K.Hasegawa, H.Sugiyama, A large scale experimental comparison of batch and continuous technologies in pharmaceutical tablet manufacturing using ethenzamide, International Journal of Pharmaceutics 559 (2019) 210-219. https://doi.org/10.1016/j.jpharm.2019.01.028

[18] M.Aravinthraj, F.L.A.Khan, J.Udayaseelan, D.Rajkumar, Molecular interactions between the mixtures of ethyl, propyl amines and 2-nitrobenzoic acid in 1,4-dioxane by DFT and dielectric relaxation analysis, Materials Today: Proceedings, https://doi.org/10.1016/j.matpr.2020.01.202

[19] Y.Hasegawa, T.Muraki, T.Tokuyama, H.Iwaki, M.Tatsuno, P.C.Lau, A novel degradative pathway of 2nitrobenzoate via 3-hydroxyanthranilate in pseudomonas fluorescens strain KU-7, FEMS Microbiol. Lett. 190 (2000) 185-190. https://doi.org/10.1111/j.1574-6968-2000.tb09284.x

[20] V.M.Hariprasad, S.K.Nechipadappur, D.R.Trivedi, Cocrystals of ethenzamide: Study of structural and physicochemical properties, Cryst. Growth Des. 16 (2016) 4473-4481. 
[21] Gaussian 09, Revision D.01, M. J. Frisch, G. W. Trucks, H. B. Schlegel, G. E. Scuseria, M. A. Robb, J. R. Cheeseman, G. Scalmani, V. Barone, B. Mennucci, G. A. Petersson, H. Nakatsuji, M. Caricato, X. Li, H. P. Hratchian, A. F. Izmaylov, J. Bloino, G. Zheng, J. L. Sonnenberg, M. Hada, M. Ehara, K. Toyota, R. Fukuda, J. Hasegawa, M. Ishida, T. Nakajima, Y. Honda, O. Kitao, H. Nakai, T. Vreven, J. A. Montgomery, Jr., J. E. Peralta, F. Ogliaro, M. Bearpark, J. J. Heyd, E. Brothers, K. N. Kudin, V. N. Staroverov, T. Keith, R. Kobayashi, J. Normand, K. Raghavachari, A. Rendell, J. C. Burant, S. S. Iyengar, J. Tomasi, M. Cossi, N. Rega, J. M. Millam, M. Klene, J. E. Knox, J. B. Cross, V. Bakken, C. Adamo, J. Jaramillo, R. Gomperts, R. E. Stratmann, O. Yazyev, A. J. Austin, R. Cammi, C. Pomelli, J. W. Ochterski, R. L. Martin, K. Morokuma, V. G. Zakrzewski, G. A. Voth, P. Salvador, J. J. Dannenberg, S. Dapprich, A. D. Daniels, O. Farkas, J. B. Foresman, J. V. Ortiz, J. Cioslowski, and D. J. Fox, Gaussian, Inc., Wallingford CT, 2013.

[22] R. Dennington, T. Keith, J. Millam, Semichem Inc., Shawnee Mission KS, GaussView, Version 5, 2009.

[23] A.W.Schuttelkopt, D.M.F.van Aalten, PRODRG: a tool for high-throughput crystallography of proteinligand complexes, Acta Crystallogr. D Biol. Crystallogr. 60 (2004) 1355-1363.

https://doi.org/10.1107S0907444904011679\

[24] B.S.Gangadharappa, R.Sharath, P.D.Revanasiddappa, V.Chandramohan, M.Balasubramaniam, T.P.Varghineni, Structural insights of metallo-beta-lactamase revealed an effective way of inhibition of enzyme by natural inhibitors, J. Biomol. Struct. Dyn. 38 (2020) 3757-3771.

https://doi.org/10.1080/07391102.2019.1667265

[25] D.S.N.B.K.Prasanth, M.Murahari, V.Chandramohan, S.P.Panda, L.R.Atmakuri, C.Guntupalli, In silico identification of potential inhibitors from cinnamon against main protease and spike glycoprotein of SARS CoV-2, J. Biomol. Struct. Dyn. (2020). https://doi.org/10.1080/07391102.2020.1779129

[26] R.Kumari, R.Kumar, A.Lynn, g_mmpbsa-a GROMACS tool for high-throughput MM-PBSA calculations, J. Chem. Inf. Model. 54 (2014) 1951-1962. https://doi.org/10.1021/ci500020m

[27] Y.S.Mary, H.T.Varghese, C.Y.Panicker, T.Thiemann, A. A.Al-Saadi, S.A.Popoola, C.Van Alsenoy, Y.Al Jasem, Molecular conformational analysis, vibrational spectra, NBO, NLO, HOMO-LUMO and molecular docking studies of ethyl 3-(E)-(anthracen-9-yl)prop-2-enoate based on density functional theory calculations, Spectrochim. Acta 150 (2015) 533-542.

[28] C.S.C.Kumar, C.Y.Panicker, H.-K.Fun, Y.S.Mary, B.Harikumar, S.Chandraju, C.K.Quah, C.W.Ooi, FT-IR, molecular structure, first order hyperpolarizability, HOMO and LUMO analysis, MEP and NBO analysis of 2-(4-chlorophenyl)-2-oxoethyl 3-nitrobenzoate, Spectrochim. Acta 126 (2014) 208-219. https://doi.org/10.1016/j.saa.2014.01.145

[29] N.P.G.Roeges, A guide to the complete interpretation of infrared spectra of organic structures, John Wiley and Sons Inc., New York, 1994. 
[30] P.R.K.Rani, Y.S.Mary, A.Fernandez, S.A.Priya, Y.S.Mary, R.Thomas, Single crystal XRD, DFT investigations and molecular docking study of 2-((1,5-dimethyl-3-oxo-2-phenyl-2,3-dihydro-1 H-pyrazol-4yl)amino)naphthalene-1,4-dione as a potential anti-cancer lead molecule, Computational Biology and Chemistry 78 (2019) 153-164. https://doi.org/10.1016/j.compbiolchem.2018.11.022

[31] E.D.Glendening, A.E.Reed, J.E.Carpenter, F.Weinhold, NBO version 3.1, Gaussian Inc., Pittsburgh, PA, 2003.

[32] Y.S.Mary, K.Raju, C.Y.Panicker, A.A.Al-Saadi, T.Thiemann, C.Van Alsenoyo, Molecular conformational analysis, vibrational spectra, NBO analysis and first hyperpolarizability of (2E)-3-phenylprop-2-enoic anhydride based on density functional theory calculations, Spectrochim. Acta 128 (2014) 638-646. https://doi.org/10.1016/j.saa.2014.02.194

[33] A.Erxleben, Cocrystal applications in drug delivery, Pharmaceutics 12 (2020) 1-3. https://doi.org/10.3390/pharmaceutics12090834

[34] A.Chakraborty, E.Kobzev, J.Chan, G.H.De Zoysa, V.Sarojini, T.J.Piggot, J.R.Allison, Molecular dynamics simulation of the interaction of two linear battacin analogs with model gram-positive and gram-negative bacterial cell membranes, ACS Omega 6 (2021) 388-400.

https://doi.org/10.1021/acsomega.0c04752

[35] D.Schneidman-Duhovny, Y.Inbar, R.Nussinov, H.J.Wolfson, PatchDock and SymmDock: servers for rigid and symmetric docking, Nucl. Acids Res. 33 (2005) W363-W367. https://doi.org/10.1093/nar/gki481

[36] Y.S.Mary, Y.S.Mary, K.S.Resmi, R.Thomas, DFT and molecular docking investigations of oxicam derivatives, Heliyon 5 (2019) e02175. https://doi.org/10.1016/j.heliyon.2019.e02175

[37] V.V.Aswathy, S.Alper-Haya, G.Yalcin, Y.S.Mary, C.Y.Panicker, P.J.Jojo, F.Kaynak-Ondurg, S.Armakovic, S.J.Armakovic, I.Yildiz, C.Van Alsenoy, Modification of benzoxazole derivative by bromine-spectroscopic, antibacterial and reactivity study using experimental and theoretical procedures, J. Mol. Struct. 1141 (2017) 495-511. https://doi.org/10.1016/j.molstruc.2017.04.010

[38] J.L.Arolas, G.M.Popowicz, S.Bronsoms, F.X.Aviles, R.Huber, T.A.Holak, S.Ventura, Study of a major intermediate in the oxidative folding of leech carboxypeptidase inhibitor: Contribution of the fourth disulfide bond, Journal of Molecular Biology 352 (2005) 961-975.

https://doi.org/10.1016/j.jmb.2005.07.065

[39] A.K.Park, I.-S.Kim, H.Do, B.W.Jeon, C.W.Lee, S.J.Roh, S.C.Shin, H.Park, Y.- S.Kim, Y.-H.Kim, H.-S.Yoon, J.H.Lee, H.-W.Kim, Structure and catalytic mechanism of monodehydroascorbate reductase, MDHAR, from oryza sativa L.japonica, Scientific Reports 6 (2016) 33903. https://doi.org/10.1038/srep33903

[40] B.L.Stoddard, P.L.Howell, D.Ringe, G.A.Petsko, The 2.1.ANG resolution of iron superoxide dismutase from pseudomonas ovalis, Biochemistry 29 (1990) 8885-8893. https://doi.org/10.1021/bi00490a002 
[41] J.Bains, M.J.Boulanger, Biochemical and structural characterization of the paralogous benzoate CoA ligases from burkholderia xenovorans LB400: Defining the entry point into the novel benzoate oxidation (box) pathway, Journal of Molecular Biology 373 (2007) 965-977.

https://doi.org/10.1016/j.jmb.2007.08.008

[42] Y.S.Mary, Y.S.Mary, A.Bielenica, S.Armakovic, S.J.Armakovic, V.Chandramohan, M.Dammalli, Investigation of the reactivity properties of a thiourea derivative with anticancer activity by DFT and MD simulations, Journal of Molecular Modeling 27 (2021) 217. https://doi.org/10.1007/s00894-021-04835-9

[43] Y.S.Mary, Y.S.Mary, Adsorption of phenothiazine derivatives on graphene-DFT, docking and MD simulation, Polycylic Aromatic Compounds (2021). https://doi.org/10.1080/10406638.2021.1946570

[44] Y.S.Mary, Y.S.Mary, K.S.Resmi, S.Sarala, R.Yadav, I.Celik, Modeling the structural and reactivity properties of hydrazono methyl-4H-chromen-4-one derivatives-wavefunction-dependent properties, molecular modelling, and dynamics simulation studies, Journal of Molecular Modeling, 27 (2021) 186. https://doi.org/101.007/s00894-021-04800-6

[45] Y.S.Mary, Y.S.Mary, S.Armakovic, S.J.Armakovic, R.Yadav, I.Celik, P.Mane, B.Chakraborty, Stability and reactivity study of bio-molecules brucine and colchicines towards electrophile and nucleophile attacks: Insight from DFT and MD simulations, Journal of Molecular Liquids 335 (2021) 116192. https://doi.org/10.1016/j.molliq.2021.116192

\section{Figures}

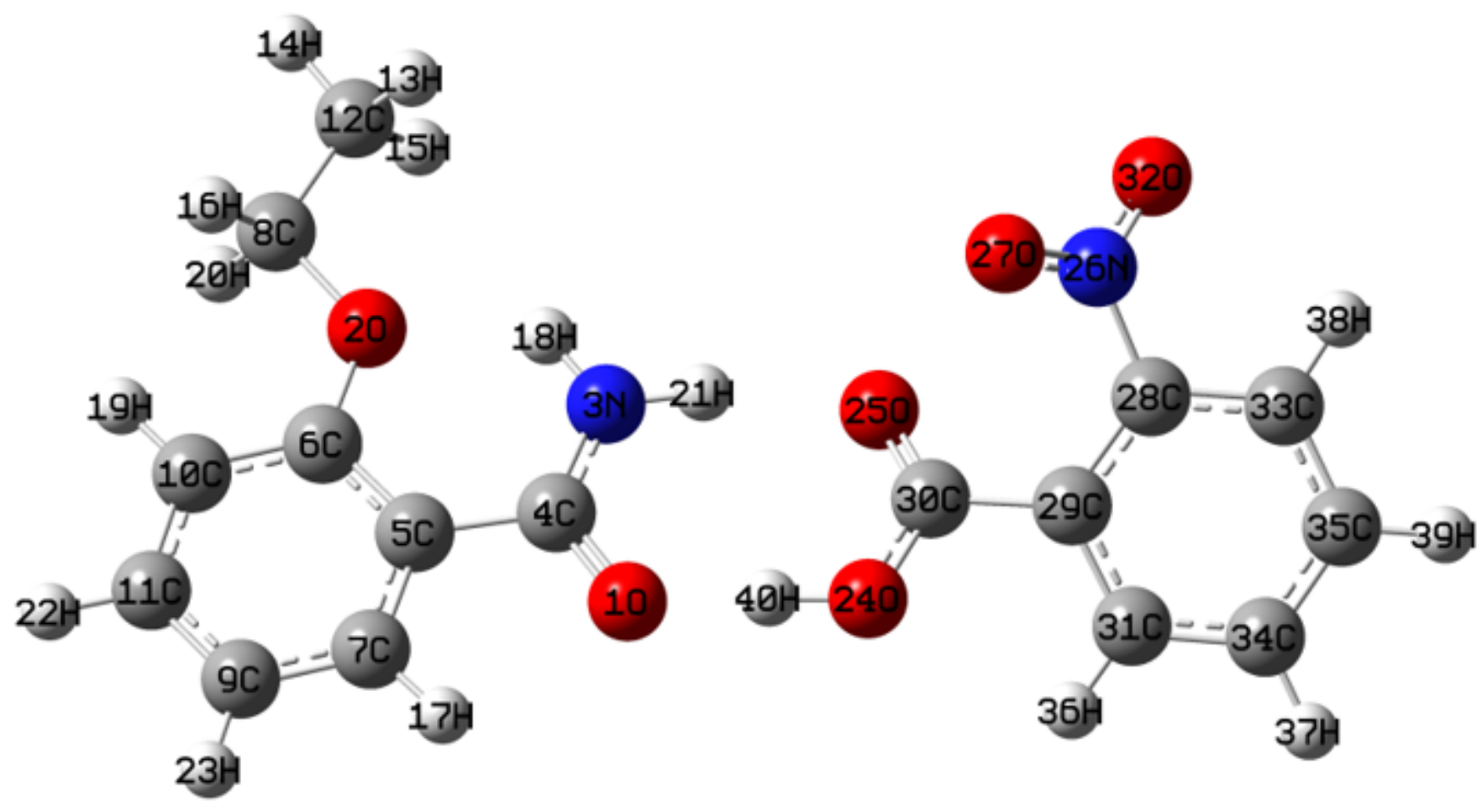


Optimized geometry of EA-NBA
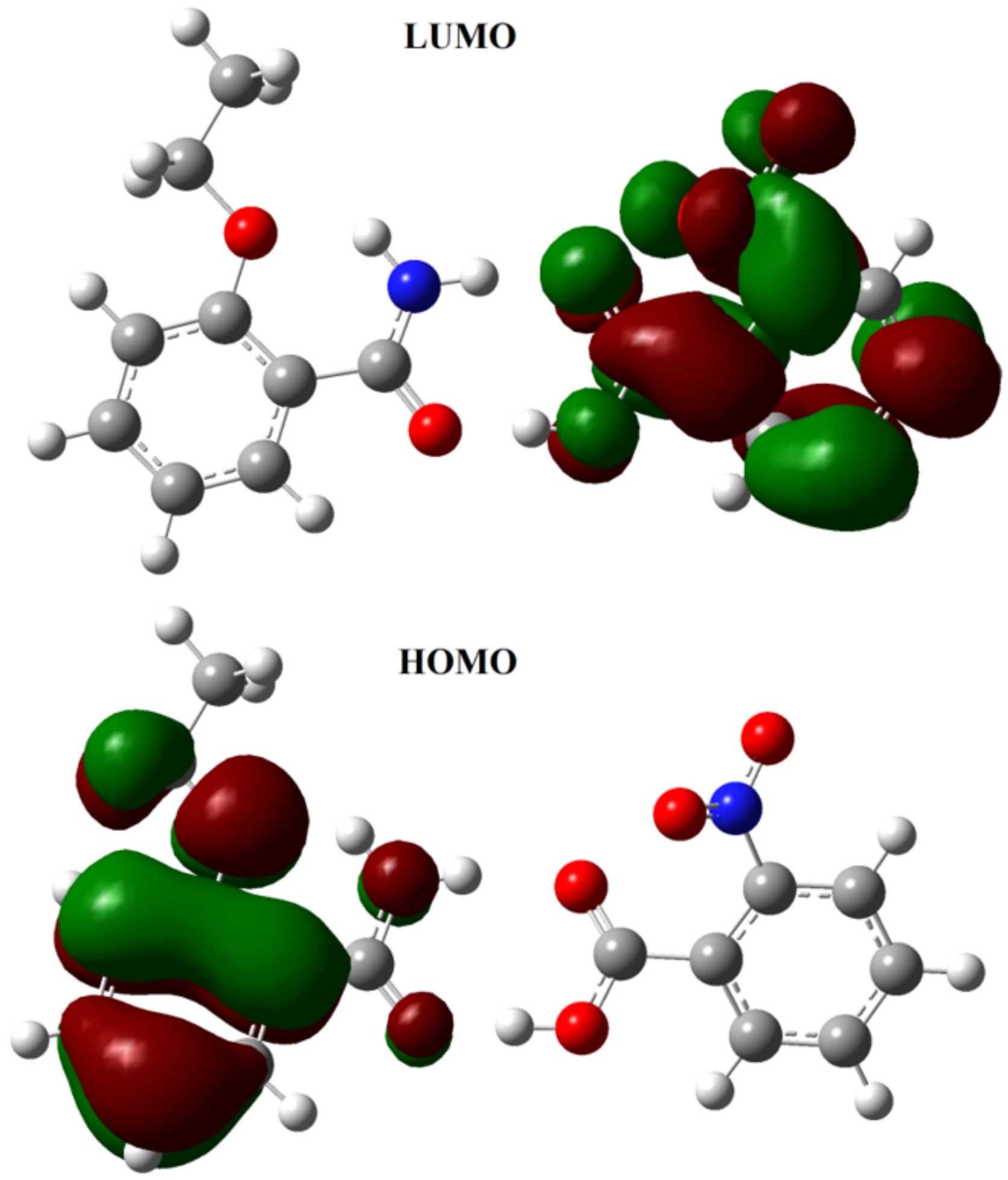

Figure 2

HOMO-LUMO plots of EA-NBA 


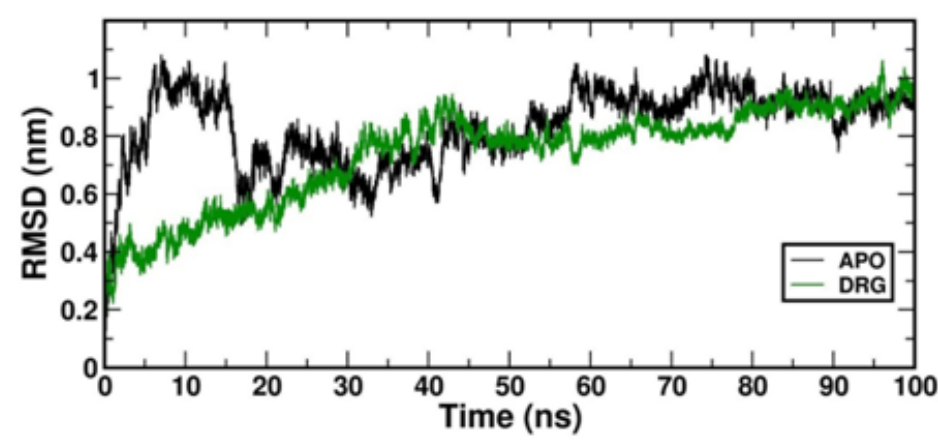

(a)

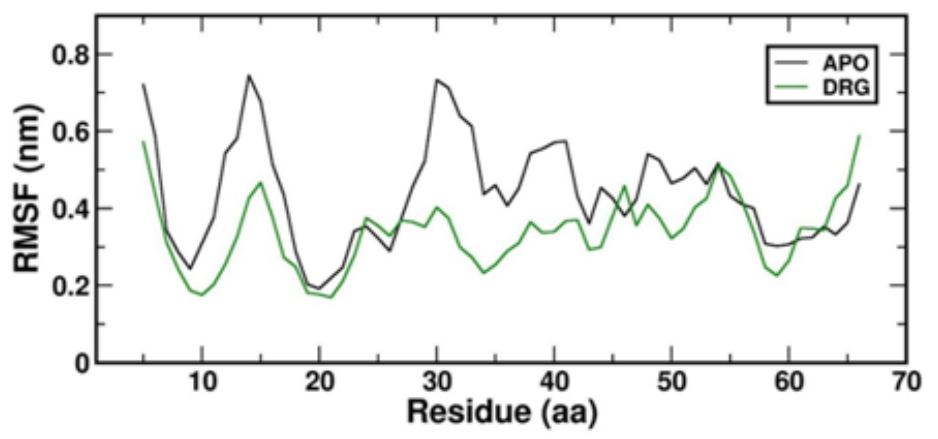

(c)

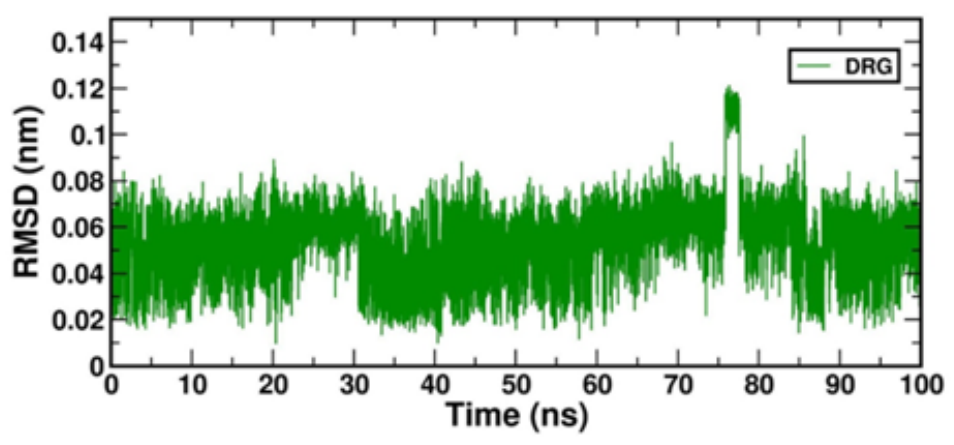

(b)

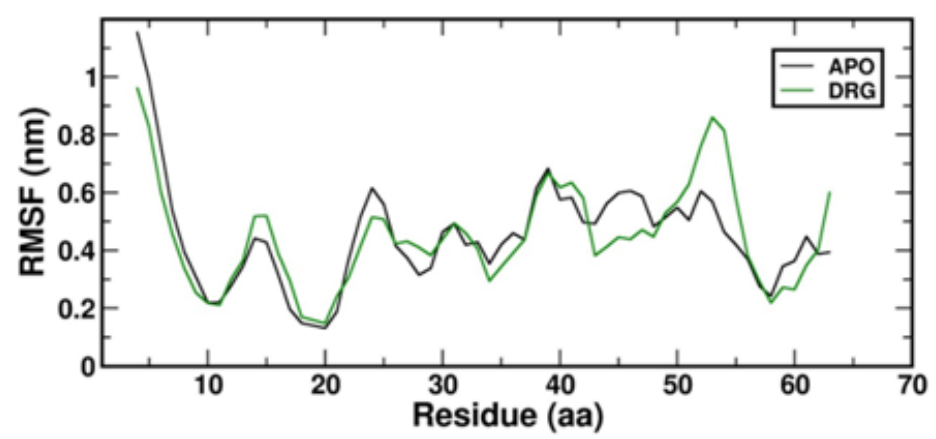

(d)

Figure 3

(a) RMSD of backbone atoms of apo and its complex with ligand complex (b) RMSD of back bone atoms of ligand complex (c) RMSF of c-alpha atoms of apo and its complex with ligand-chain A (d) RMSF of calpha atoms of apo and its complex with ligand-chain B

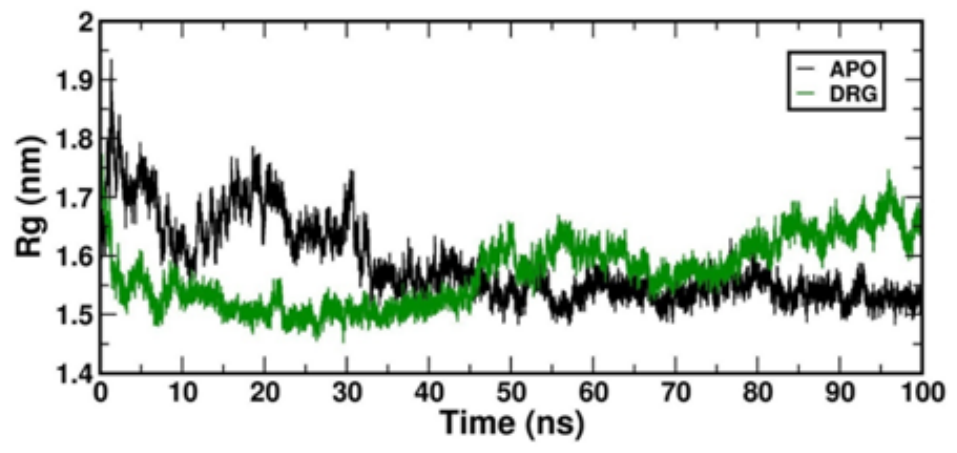

(a)

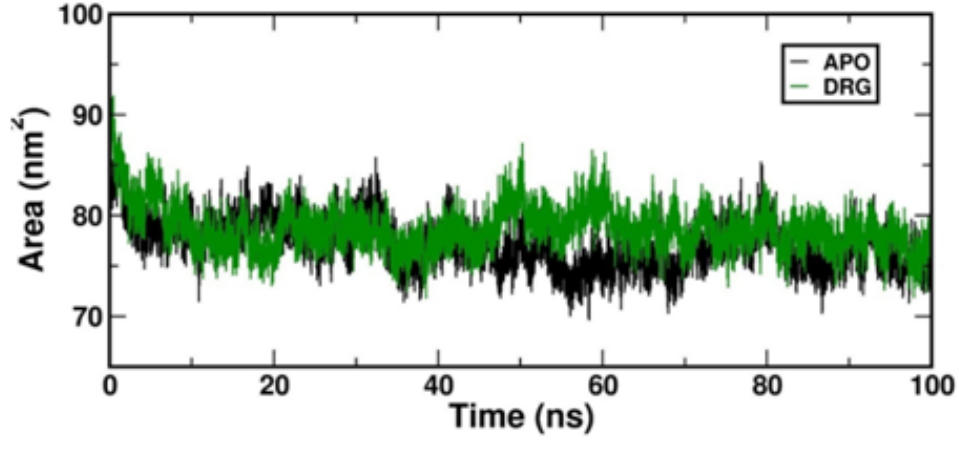

(b)

Figure 4

(a) Rg of backbone atoms of apo and its complex with ligand (b) SASA of backbone atoms of apo and its complex with ligand 


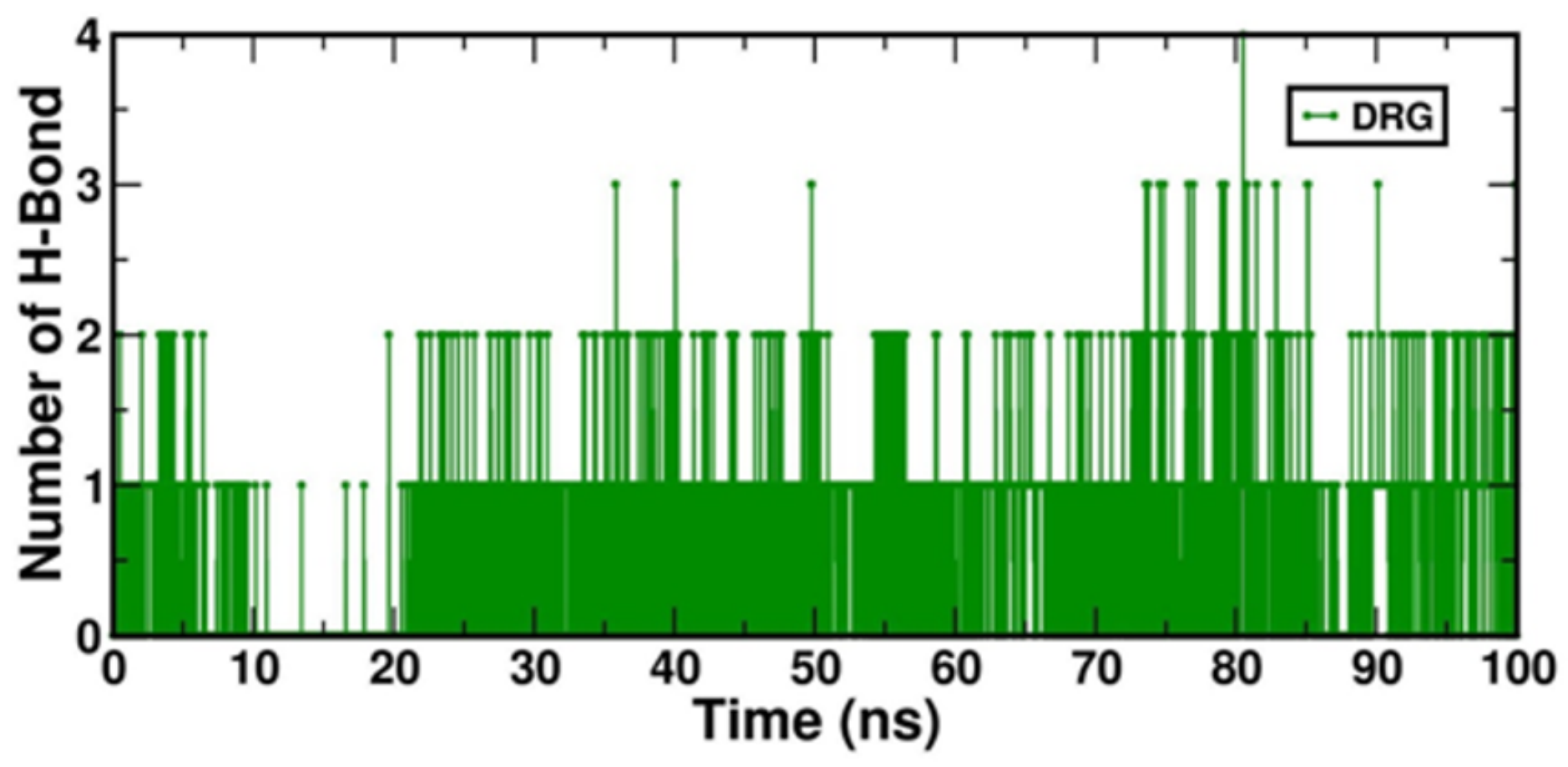

Figure 5

$\mathrm{H}$-bond complex with ligand

\section{Supplementary Files}

This is a list of supplementary files associated with this preprint. Click to download.

- graphicalabstract.docx

- Fig.S1S10.docx

- tableS1S5.docx 